Environmental Pollution

November 2018, Volume 242, Part A, Pages 519-527

http://dx.doi.org/10.1016/i.envpol.2018.06.095

http://archimer.ifremer.fr/doc/00448/55965/

(c) 2018 Elsevier Ltd. All rights reserved

\title{
Polycyclic aromatic hydrocarbons in surface sediments of the mid-Adriatic and along the Croatian coast: Levels, distributions and sources
}

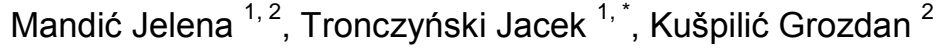 \\ ${ }^{1}$ Ifremer, Centre Atlantique, Département des Ressources Biologiques et Environnement, BP 21105, \\ 44311 Nantes Cedex 03, France \\ ${ }^{2}$ Institute of Oceanography and Fisheries, IOF, Šetalište I. Meštrovića 63, 21000 Split, Croatia \\ *Corresponding author : Jacek Tronczyński, email address : itronczy@ifremer.fr
}

\begin{abstract}
:
This study provides contamination levels, distributions and source apportionment of PAHs in surface sediments in the mid-Adriatic and along the Croatian coast. Median summed concentrations of parent and alkyl-PAHs are circa 10 times lower in the off-shore transect stations of the mid-Adriatic (22.3 and $18.2 \mu \mathrm{g} . \mathrm{kg}-1$ d.w.) than the ranges determined at the coastal stations, including those of Kaštela bay (227-331 and 11.7-197 $\mu$ g.kg-1 d.w., respectively). The highest levels, circa 20 times higher, were found in Šibenik bay (median 6603 and $3051 \mu \mathrm{g} . \mathrm{kg}-1$ ). The overall range of PAH concentrations spans more than 2000 times between the lowest and the highest contamination level. The geographical distributions reflect the presence of strong gradients at local and regional scales. A major factor influencing sedimentary PAH distributions at local scale appears to be the distance from their known continental and coastal upstream emission sites (urban, industrial, harbour ...), whereas at regional scale, this distribution depends more on the routes of entry of PAHs into the study area. Two combustion and one petroleum model source profiles of PAHs were determined by alternative least square analysis. Benzo[b+j]fluoranthenes and fluoranthene/pyrene are compounds characterizing two pyrogenic sources respectively, while signatures of alkyl-substituted homologues (phenanthrenes/anthracenes, fluranthenes/pyrenes, chrysenes and dibenzothiophenes) delineate a petrogenic source profile. The quantitative apportionment of source contributions shows significant geographical differences, with a dominant petrogenic source found along the mid-Adriatic transect (approximately $74 \%$ ) and in Kaštela bay (61\%). In the coastal sediments about a fifty-fifty contamination mix is assigned to a petrogenic/pyrogenic source of PAHs (47\% and $53 \%$ respectively), whereas in Šibenik bay a strong predominance is apportioned to the combustion compounds (81\%).
\end{abstract}




\section{Graphical abstract}

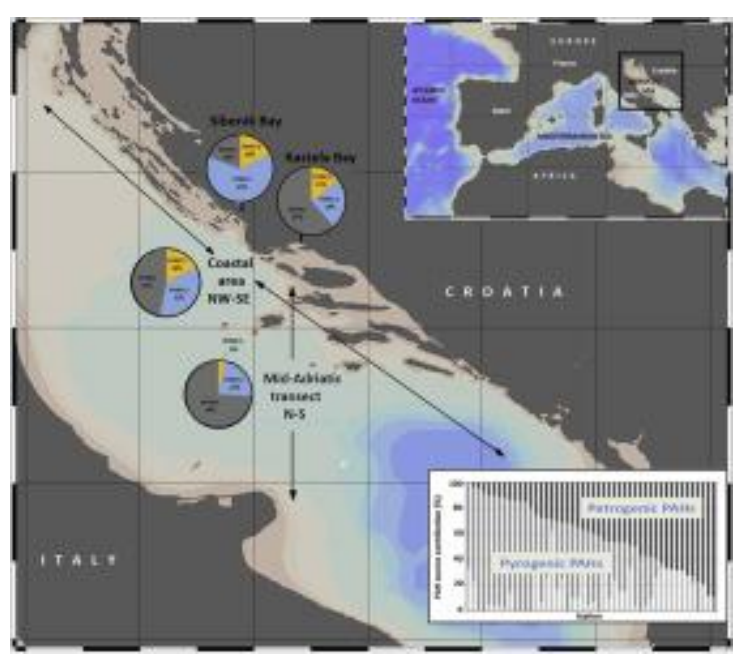

\section{Highlights}

- The high levels of sedimentary PAHs are related to discharge/emission sites. The strong gradients of PAH levels are found at local and regional scales. The parent and alkyl homologues appear as first-hand indicators of PAH sources. Petrogenic PAHs are spatially more widespread in the mid Adriatic. Pyrogenic PAHs are more closely related to the point discharge sources.

Keywords: Marine sediments, Polycyclic aromatic hydrocarbons (PAHs), Source profiles Source apportionment, Source-receptor models 
44 Polycyclic aromatic hydrocarbons (PAHs) are one of the most widespread organic pollutants in

45 current marine and terrestrial environments (Laflamme and Hites 1978). Although certain of these

46 hydrocarbons also have natural origins, anthropogenic PAHs predominate in today's

47 environments (Neff 1979, Venkatesan 1988, Wakeham et al. 1980). A large number of

48 anthropogenic PAHs are recognized as strong mutagens and carcinogens (Allen et al. 1998,

49 Durant et al. 1998), representing a significant public health concern and threats to ecosystems.

50 Actually, PAHs are on the lists of priority pollutants and substances in the USA and Europe,

51 aiming at better control, regulation and the reduction of water and air pollution by these

52 chemicals (EPA 2014, EU 2013). The effective mitigation and remediation measures of this

53 pollution require an understanding of the various sources of $\mathrm{PAH}$ contributions found in a

54 specific region. In the marine environment, the major sources of anthropogenic PAHs are related

55 to releases of crude petroleum and its numerous derivatives and to all inputs of compounds

56 derived from the incomplete combustion of biomass and fossil- and modern bio-fuels (Fraser et

57 al. 1998, Dachs et al. 2002, Deyme et al. 2011). The pathways of petroleum-derived PAHs are

58 mainly regular spillages from various maritime activities (transport, oil exploitation, harbour

59 operations...) as well as accidental oil spills, whereas combustion-derived PAHs (generally from

60 marine and continental transport, power and heat plants, residential warming and specific

61 industries) enter the marine environment mainly via the atmospheric fallout of soot particles and 
continental watershed runoff, including, direct discharges of storm waters from coastal large

63 coastal cities and industrialized sites (Lima et al. 2005, Guo et al. 2007, Gonul and Kucuksezgin 2012). Due to strong sorption propensity, many environmental PAHs are associated with particles (Karickhoff et al. 1979, Dachs et al. 2002, Zhao et al. 2013). Despite their long-range global atmospheric transport (Fernandez et al. 2000, EEA 2013), PAHs are also deposited in large amounts in coastal sediments, showing a strong decline of their concentrations with increasing distance from the coast (Lipiatou et al. 1997, Tsapakis et al. 2003, Cathalot et al. 2013). In this context, complementary and alternative approaches for the characterization of PAH sources are continuously developed. Common emissions and discharge inventory studies have

71 provided emerging regional and local trends, and a generally good correspondence between emissions of PAHs and records of energy production and fossil-fuels consumption (Zhang et al. 2009, EEA 2013, Shen et al. 2013). However, highly variable emission factors have been reported, thus indicating great uncertainties in the environmental inventories of PAHs (Jenkins et al. 1996, Pacyna et al. 2003, Johansson et al. 2004, Lee et al. 2005, Chen et al. 2005). Many reported studies are based on the understanding of spatial distributions and the identification of point emission sources, the interpretations of compositional molecular signature fingerprints and diagnostic source ratios of specific PAHs determined in diverse receptor compartments, namely, the atmosphere, sediments, biota (Douglas et al. 1996, Yunker et al. 2002, Neff 2002,

80 Christensen et al. 2004, Zhang et al. 2005). More recently, chemometric analyses have also been 81 applied for PAH source characterization (Larsen and Baker 2003, Li et al. 2003, Comero et al 2009, Stout and Graan 2010). This approach is often referred to as the source apportionment method, allowing the determination of a number of contributing sources as chemical profiles

84 ("end-member" signature fingerprints) and the relative amounts of each source present in a 85 sample. For instance, in the urban atmosphere of Baltimore, based on multivariate statistics and 
86

87

88

89

90

91

92

93

94

95

96

97

98

99

100

101

102

103

104

105

106

107

108

109

receptor environment models, such methods allowed the resolution and apportionment of up to six combustion sources of PAH (Larsen and Baker 2003). Finally, the radiocarbon analysis of individual PAH compounds in different sedimentary and atmospheric environments was also used as the most reliable method to determine the relative contributions of fossil fuel and biomass combustion sources of PAHs (Mcare et al. 2000, Reddy et al. 2002, Mandalakis et al. 2004, White et al. 2005, Mandalakis et al. 2005, Kumata et al. 2006, Cathalot et al. 2013). Such determinations, using PAHs as excellent molecular tracers of combustion particles, may also contribute to more fundamental assessments of pyrogenic/combustion carbon contributions to various pools of organic carbon budgets, and therefore are carried out as well in the context of global climate change studies (White et al. 2005, Dickens et al. 2004). However, this later method is very demanding and reserved for specialized laboratories.

In this study, we report on PAH levels, distributions and source characterization determined in the surface sediment of the mid-Adriatic and along the Croatian coast. Extensive analyses of PAHs in the sediment samples included unsubstituted parent compounds, alkyl-substituted homologues and sulphur heterocyclic compounds. Four zones were studied: the mid-Adriatic transect, a coastal survey from the north-west to the south-east along the Croatian shoreline and two urban-industrial zones: Šibenik and Kaštela bays. This regional/local geographical coverage was arranged so that it included known and suspected contaminant emission sites and reference sites away from direct pollution sources. Finally, PAH source characterization in this study is based on the wide range of analyzed compounds, together with geographical distribution data it also includes an examination of carefully selected meaningful source-specific diagnostic ratios and correlations, explanatory multivariate statistics by principal component (PCA) and hierarchical cluster (HCA) analyses, and chemometrics receptor environment analysis using the alternative least square (ALS) calculation method. The results include the identification of PAH 
110 chemical source profiles and the quantification of the relative contributions of these sources in

111 the studied areas. Consequently the results presented provide a coherent set of reference data on

112 the contamination of marine sediment by PAHs in the mid-Adriatic and along the Croatian coast.

113 2. Materials and methods

\section{$114 \quad$ 2.1. Sample collection and pre-treatment}

115 Sediment samples were collected from the $R / V$ Bios 2 (IOF/Croatia) during three campaigns in

116 2013. In total, 29 stations were sampled in the four studied areas: the mid-Adriatic transect, a 117 coastal survey from north-west to south-east along the Croatian shoreline (from $44.49005 \mathrm{~N}$ and 118 15.01010 E to 42.63339 N and 18.02187 E) and two urban-industrial sites, Šibenik and Kaštela 119 bays (Fig. 1, Table S-1 and S-2). Approximately, 200 grams of wet surface sediment were 120 manually sub-sampled using stainless steel spatula from the centre of Van Veen Grab. The grab 121 sampling may roughly represent $0.1 \mathrm{~m}^{2}$ of surface sediment. The sediment sub-samples were 122 wrapped in pre-cleaned aluminium foil and subsequently frozen on-board at $-20^{\circ} \mathrm{C}$. Samples were 123 transferred frozen to the laboratory, freeze-dried and subsampled for the chemical and sediment 124 characterization analysis. The sediment aliquots for PAH analyses, were further sieved through a $1252 \mathrm{~mm}$ stainless steel screen and stored in pre-cleaned glass jars until laboratory analyses.

\subsection{Grain size distribution}

127 A weighted sample aliquot of dry granular sediment is processed through a nested set of 128 standardized sieves with progressively smaller openings of: $4,2,1,0,5,0,25,0,125$ and 0,063 $129 \mathrm{~mm}$. The smaller than $0.063 \mathrm{~mm}$ sediment fraction was determined by the aerometric method 130 according to Casagrande (Ostrowska et al, 1991). The fractions were described according to 131 Wentworth Grade Scale (1922): gravel-sized particles have a nominal diameter of $2 \mathrm{~mm}$; sand132 sized particles have nominal diameters of $<2 \mathrm{~mm}$ to $>63 \mu \mathrm{m}$; silt-sized particles have nominal 
133 diameters of $<62.5 \mu \mathrm{m}$ to $>4 \mu \mathrm{m}$; and clay is $<4 \mu \mathrm{m}$. The parameters calculated for grain size

134 include: mean, median, sorting and skewness (Table S-2).

135

136

\subsection{Organic matter determination}

The amount of organic matter was determined by gravimetric measurements as lost by ignition at $450{ }^{\circ} \mathrm{C}$. Approximately $0.5 \mathrm{~g}$ of a dried, ground and sieved $(4 \mathrm{~mm})$ sediment sample aliquot is weighted precisely in a crucible. Crucibles are then dried at $110{ }^{\circ} \mathrm{C}$ for 24 hours. When cooled, the crucibles are reweighed and treated with $30 \% \mathrm{H}_{2} \mathrm{O}_{2}$. Once the samples have been dried, the crucibles are placed in a furnace and ignited at $450{ }^{\circ} \mathrm{C}$ for six hours.

\subsection{PAH analysis}

The analytical method is described in more detail elsewhere (Tronczyński et al. 2004). Briefly, the analysis of PAHs in the surface sediment included different groups of unsubstituted parent compounds (PAH), alkyl-substituted homologues (C-PAH) and both unsubstituted and alkyl-substituted polycyclic aromatic sulphur heterocyclic compounds (SPAH and C-SPAH). The concentrations were determined for individual compounds and for their alkyl-substituted homologue groups (Table S-3). Aliquots of dry sediments $(5-20 \mathrm{~g})$ of each sample were extracted twice using dichloromethane by accelerated solvent extraction (Dionex ASE 200). Prior to extraction, sediment samples were spiked with perdeuterated recovery standards (phenanthrene- $d_{10}$, benzo[e]pyrene- $d_{12}$ fully deuterium labelled compounds). The organic extracts were concentrated using rotary evaporation and nitrogen gas and then purified and fractionated by a two-layer 5\% deactivated silica/alumina column. The PAHs were analysed and quantified by gas chromatography coupled to the mass selective detectors (GC-MS Agilent Technologies models 7890/5975). Prior to GC-MS analysis, all sample extracts and calibration solutions in auto-sampler vials were quantitatively spiked using a robotic auto-sampler with an internal standard mixture containing deuterated compounds: acenaphtene- $d_{10}$, fluorene- $d_{10}$, 
pyrene- $d_{10}$, benz $[a]$ antracene- $d_{12}$ and indeno[1,2,3-cd]pyrene- $d_{12}$. The quantification of individual

158 PAH compounds and group of their alkyl-homologues in the samples was carried out by using

159 corrected response of GC-MS with the response of correspondent surrogate quantification

160 standard. The replicate analysis of EC-2 NWRI (Environment Canada) sediment samples of

161 certified reference material for PAHs was used for the assessment of the precision and accuracy

162 of the entire analytical protocol. The accuracy was between 60 and $93 \%$ of certified values $(n=$

163 6) and relative standard deviation of repeated analysis was better than $\pm 16 \%$ for all quantified

164 PAH analytes in the sediment samples. Average recovery of standards (phenanthrene- $d_{10}$ and

165 benzo[e]pyrene- $\left.d_{12}\right)$ was $73 \pm 16 \%$ while samples with low recovery $(<50 \%)$ were excluded.

166

167

168

169

170

171

172

173

174

175

176

177

178

179

\subsection{Statistics}

Hierarchical cluster (HCA) and principal component analysis (PCA) of PAH data were performed using Pirouette multivariate data analysis software (Infometrix 2014). For both analyses the PAH concentration data were pre-processed by autoscaling, i.e. mean-centering followed by variance scaling. For HCA we used Euclidean distance between samples, expressed on the standard scale of similarity where a value of 1 is assigned to identical samples and a value of 0 to the most dissimilar samples. The samples were clustered by the incremental link method used to calculate inter-cluster distances (i.e. a sum of squares approach). For PCA, total variability of the original PAH data is represented by a minimum number of factors with a subsequent varimax (normal) rotation of factors, which maximizes the variance of the loadings by sequentially rotating PCA loadings pair-wise. Finally, in the receptor model, the problem is considered as a solution of the chemical mass balance equation in a number of source profiles, and their contributions to each individual sample. The number of sources is related to total variance, where the alternating least square (ALS) calculation requires an iterative technique to 
180 obtain the most meaningful solution, that is, the best fitting compositions and profiles (Tauler et

181 al. 1993). The algorithm used in the present estimates, is based on "convexity" calculation

182 (Grande and Manne 2000), it finds the purest "shapes" in the original PAH concentration data,

183 determining row-wise estimates of profiles, and column-wise estimates of composition

184 (Pirouette, Infometrix 2014). The source profiles are interpreted as source types

185 (combustion/pyrogenic and petroleum/petrogenic), also using known emission/discharge

186 information and geographical distribution results.

\section{3. Results and discussion}

$188 \quad$ 3.1. Levels, spatial distributions and gradients

189 Concentrations of main suites of PAH determined in the sediments of four studied areas (mid-

190 Adriatic transect, coastal transect, Kaštela and Šibenik bays) are summarized in Table 1 and

191 further detailed in SI (Fig. S-1 and Table S-4). The summed concentrations of parent and alkyl-

192 PAH ranged from 8.50 to $18348 \mu \mathrm{g} \mathrm{kg}^{-1}$ and from 2.95 to $5770 \mu \mathrm{g} \mathrm{kg}^{-1}$ dry weights, respectively.

193 Levels of parent and alkylated sulphur heterocyclic PAHs ( $\Sigma$ S-PAH, $\Sigma$ CS-PAH) were within the 194 ranges $0.336-514 \mu \mathrm{g} \mathrm{kg}^{-1}$ and $0.292-977 \mu \mathrm{g} \mathrm{kg}^{-1}$ d.w., respectively.

195 The lowest concentrations of summed total PAHs ( $\mathrm{TT}-\mathrm{PAH})$, were determined along the mid196 Adriatic transect ( $\Sigma \mathrm{T}-\mathrm{PAH}$, range $11.7-282 \mu \mathrm{g} \mathrm{kg}{ }^{-1}$, d.w.), the intermediate levels were 197 determined in the coastal and Kaštela bay sediments ( $\Sigma \mathrm{T}-\mathrm{PAH}$, range $117-2580 \mu \mathrm{g} \mathrm{kg}^{-1}$, d.w.) 198 and the highest level of contamination by PAHs was found in Šibenik bay ( $\Sigma T$ T-PAH, range 6610 $199-24576 \mu \mathrm{g} \mathrm{kg}^{-1}$, d.w.). The very low concentrations determined along the transect (especially at 200 off-shore stations TS1 and TS2) correspond to PAH levels reported in sediments from open sea 201 areas in the eastern Mediterranean and Cretan Sea (Lipiatou et al. 1997, Tsapakis et al. 2003, 202 Gogou et al., 2000, Gonul and Kucuksezgin 2012) and also from remote locations of the world 203 oceans, such as the Barents Sea (Savinov et al. 2003) and arctic lakes (Fernandez et al. 2000). 
204 These levels remain within the range of background reference concentrations of PAH in marine

205 sediments (Ospar/Ices 2004, Azoury et al. 2013, UNEP 2016). Interestingly, higher

206 concentrations along the mid-Adriatic transect were found at stations TS3 and TS5. The

207 concentrations increase systematically from TS1 to TS3 probably indicating a local concentration

208 gradient in this area. TS3 is located along the route of the densest maritime traffic in the Adriatic

209 (Morovic et al. 2015). Furthermore, a higher amount of silt and clay in the sediment at this station

210 may also contribute to the effective deposition of PAHs (Table S-2). Relatively high levels of

211 both parent and alkylated PAH homologues were also found at station TS5, which is

212 approximately 20 miles from the Italian coast. This area is affected by the backward cyclonic

213 gear that spreads contaminants introduced in the Adriatic by the Po valley watershed (Marini et

214 al. 2015). Summed parent-PAH concentrations in the majority of coastal sediments, including

215 Kaštela bay, were within the range that corresponds to the low medium contamination level,

216 which is between slightly below 100 and slightly above $400 \mu \mathrm{g} \mathrm{kg}{ }^{-1}$, d.w.(Tolosa et al. 1996,

217 Lipiatou et al. 1997, Baumard et al. 1999, Gomez-Gutierrez et al. 2007, Barakat et al. 2011,

218 Mzoughi and Chouba 2011). Relatively high concentrations (> 1000 were $\mu \mathrm{g} \mathrm{kg}^{-1}$, d.w.) were

219 found only at stations CS3 and CS10 in the coastal zone and at station KB3 in Kaštela Bay. At

220 these stations, PAH levels were 2 to 6 times higher than at adjacent sites, indicating local hot

221 spots identified near the town of Zadar (CS3), the site of a former chromium and carbide plant

222 (CS10), and at the shipyard - industrial harbour of Split in Kaštela Bay (KB3). These

223 concentrations are comparable to PAH levels reported for urbanised coastal areas (Benlahcen et

224 al. 1997, Bertolotto et al. 2003, Di Leonardo et al. 2009). In Kaštela Bay, the local gradient is

225 observed for all sampling periods, with concentrations decreasing with increasing distance from

226 the eastern part, near an industrial port (station KB3), to the central part of the bay (station KB4).

227 Furthermore, in the coastal area and Kaštela Bay, for most stations, PAH concentrations in 
228 sediments were within the range corresponding to the average pollution level generally found in

229 areas under moderate anthropogenic pressures, for instance in the Black Sea (Wakeham et al 230 1996), the eastern Mediterranean (Tsapakis et. al 2003), Porto-Tores harbour in Sardinia (De

231 Luca et al. 2004) and Daya Bay in China (Zhou and Maskaoui 2003). Finally, very low coastal 232 concentrations of parent-PAH $\left(<150 \mu \mathrm{g} \mathrm{kg}^{-1}\right)$ were determined only at two stations (CS1 and 233 CS7) characterized by high sand content. Such levels correspond to those reported for more 234 remote sea areas, with low pressures from urban and industrial activities, such as the Balearic 235 Islands (127 $\mathrm{g} \mathrm{kg}^{-1}$,d.w.) and Corsica (87 $\mathrm{g} \mathrm{kg}^{-1}$, d.w.) (Baumard et al.1998, Benlachen et al. 236 1997).

237 High and extremely high concentrations were determined in the Šibenik Bay sediments. The 238 lowest levels found were above $4000 \mu \mathrm{g} \mathrm{kg}^{-1}$,d.w. of parent-PAH, and these values compare to 239 contamination levels in highly industrialised coastal areas in the Mediterranean and worldwide, 240 such as Toulon Harbour (Benlachen et al. 1997), Barcelona Harbour (Baumard et al. 1998), 241 Napoli Harbour (Sprovieri et al. 2007) and the Bay of Mexico (Ponce-Velez et al. 2006). The 242 highest concentrations in the bay were found in the vicinity of the former ferroalloy factory 243 (stations SB4 and SB8), indicating that this historical industrial activity was the main emission 244 source of PAHs in Šibenik Bay. Very significant levels were also found in the harbour area and 245 near-shore in the western part of the Šibenik urban centre (stations SB6 and SB3). The spatial 246 distribution of PAH in the sediments suggests that contamination has spread over the entire bay. 247 However, this contamination seems to remain in Šibenik Bay, given that the PAH concentrations 248 at the closest station outside the bay (CS6), only 2.5 miles away from the entrance to the bay, are 24910 to 20 times lower (alkyl and parent-PAHs respectively) than the lowest levels determined in 250 the centre of the bay (station SB5). Indeed, limited circulation, water mass exchanges and the 
251 local hydrosedimentological regime indicate very poor sediment export to adjacent areas outside

252 Šibenik Bay (Bužančić et al. 2016, Kušpilić 2005).

253 Thus, it appears that the range of PAH concentrations in coastal and mid-Adriatic sediments 254 spans over more than 2000 times between the lowest and the highest contamination levels. In this 255 area, the spatial distributions thus reflect the presence of the strong gradients at local and regional 256 scale, in the contamination of sediments by PAHs. The major factor influencing sedimentary 257 PAH distributions at local scale appears to be the distance from their known continental and 258 coastal upstream emission sites (urban, industrial, harbour...). At a regional scale, however, this 259 distribution depends more on the routes of maritime entry of PAHs (riverine, atmospheric, 260 naval...) and their downstream dispersion, deposition dynamics and sediment type.

\subsection{Characterization of PAH sources}

262 The characterization of PAH sources in the environmental samples is generally based on the 263 examination of their chemical composition, allowing the qualitative identification of source 264 signatures (Stogiannidis and Laane 2015) and also, ultimately, the quantitative apportionment of 265 the amount of contaminants contributed by each source (Larsen and Baker 2003, Lang et al. 266 2013). Such characterization might also be supported by the examination of the geographic 267 distribution of PAH concentrations, which would eventually allow assignment of their emission 268 point sources in the studied area. Both of these approaches are selectively used in this study.

\section{$269 \quad$ 3.2.1. Geographic distributions}

270 Based only on the geographic distribution of the sedimentary PAH concentrations in the coastal 271 Adriatic, it was possible to reveal a few point emission sources of PAHs in the studied area. As 272 already discussed above, in the coastal areas characterized by different levels of contamination 273 (i.e. Šibenik Bay and the whole coastal survey including Kaštela Bay), PAH concentrations in the 274 sediments are higher in the areas near emission sources, which may be present or past (Fig. S-1). 
275 Thus, in Šibenik Bay, very high levels were found at the stations clearly related to the local point

276 source of PAHs emitted from the former ferroalloy industrial plant (stations SB4 and SB8) and

277 also from mixed sources of PAH releases from urban and harbour /marina facilities (stations

278 SB3, SB1 and SB6). Whereas, along the Croatian coast high concentrations were found near the

279 Zadar urban centre (station CS3), a former metal (iron /chromium) plant (station CS9) and the

280 industrial harbour of Split in Kaštela Bay (station KB3). All these sites should thus be

281 considered as the "hot spots" of sediment contamination by PAHs along the Croatian coast.

\subsubsection{Source indicators and classification model-building}

283 The relative PAH abundances, molecular indices and multivariate analysis allow identification 284 and classification of PAH source profiles and contributions (Stogiannidis and Laane 2015). The 285 ratio of alkyl to parent compounds ( $\Sigma \mathrm{Alkyl} / \Sigma \mathrm{PAH})$ was used to assess pyrogenic or petrogenic 286 sources of PAHs in sediments (Yunker et al. 2002). This ratio is sensitive to fresh petroleum 287 releases and was used to distinguish pre- and post-spill contamination after major oil spill events 288 (Short and Harris 1996, Law et al 1999, Tronczyński et al 2004). The threshold values depend on which parent and alkylated homologues are used for calculation of the sum of their totals but, in general a lower than 0.5 ratios are related to pyrogenic sources, whereas a ratio above 1 is more often related to a petrogenic source. In the data presented here, the $\Sigma$ Alkyl/ $\Sigma \mathrm{PAH}$ ratio varies between 0.23 and 1.17 (Table S-5). The lowest values were found in Šibenik Bay indicating the strong contribution of pyrogenic PAHs, whereas the highest ratios were determined at four stations: Kaštela Bay in the industrial northern port of Split (KB3), at transect stations TS4 and TS6 (the first representing the route with highest shipping traffic density in the Adriatic and the second is the closest to the Italian coast, as discussed above, and is influenced by the Po River

297 loads) and at station CS2, i.e.one of the northernmost inner coastal sampling sites with relatively

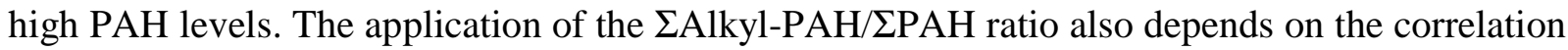


299 of two variables (Tronczyński et al. 2004). The correlation of parent PAHs with their alkyl

300 homologues thus allows to clearly distinguish the contamination by PAHs in Šibenik Bay from 301 other areas (Fig. S-2).

302 Discrete regression for the Šibenik site, definitely implies specific predominant sources in the 303 bay and that PAH composition is different in the areas outside the bay, with a clearly higher 304 relative contribution of alkyl homologues, indicating greater relative petrogenic inputs. This also 305 suggests that parent against alkyl homologue correlations and ratios might be reliable PAH 306 source indicators for both local and larger geographic areas, and that despite very high 307 concentrations, PAHs from Šibenik indeed remain confined to the bay. Moreover, such indicators 308 of PAH sources in sediments should be less sensitive to degradation/weathering processes, 309 because of the use of summed concentrations of almost all PAHs and their determined 310 homologues. In Šibenik Bay sediments, the indicators clearly withstand past contamination 311 signatures from the ferroalloy plant. These correlations also show (Fig. S-2) that in Šibenik Bay 312 the possible higher contribution of petrogenic $\mathrm{PAH}$, with a relative higher proportion of alkyl 313 homologues, may be inferred at the stations corresponding respectively to Šibenik marina (SB1), 314 the entrance to the Šibenik port (SB 2 and SB7) and one of the samples from the Šibenik fisheries 315 port (SB3) (Fig. S-2). Finally, added points of modelled source profiles of PAH from ALS 316 statistics (see below) align well with the Šibenik regression line for two combustion profiles, as 317 well as for all other stations with the regression line for a petrogenic source.

318 Analogous grouping among samples is obtained by principal component (PCA) and 319 hierarchical cluster (HCA) analyses taking into account the relationships between the 320 independent variables of all determined individual PAH compounds (Fig. S-3). The greatest 321 distance was obtained between the Šibenik Bay stations and all other stations. However, higher 322 variation and dissimilarities may be observed in Šibenik Bay, suggesting an overlap and 
323 combination of distinct PAH sources. Discrete clustering is found for the coastal survey among

324 stations KB3, CS2, CS3 and CS9 that are characterized by higher contamination, in the vicinity

325 of known emissions sources. These findings indicate overall that: geographical distribution, PAH

326 source indices and explanatory multivariate statistics allow coherent categorization of sampling

327 stations, according to the relative contributions of mainly petroleum versus combustion-derived

328 PAHs in the sediments of the studied area. Distinctive characteristics of these sources and their

329 quantitative proportion estimates in each area were further examined by the receptor environment

330 model based on chemometric multivariate statistical analysis.

$331 \quad 3.2 .3$. Source profiles and contributions

332 Chemometric analysis involving receptor environment models allows the identification of 333 source profiles (PAH fingerprints) and quantitative apportionment of such PAH sources. The 334 algorithm used in the present estimations, is based on multivariate alternating least square (ALS) 335 calculation using the iterative technique (Pirouette, Infometrix 2014). PAH model source profiles, 3362 combustion profiles and 1 petroleum profile, were obtained by alternative least square analysis 337 (Fig. 2).

338 Both combustion profiles are characterized by higher abundances of unsubstituted PAHs and 339 by "skewed" patterns of parent/alkyl-substituted compounds (phenanthrenes/anthracenes, 340 fluranthenes/pyrenes and chrysenes). In these profiles, greater alkylation homologues were less 341 abundant $(\mathrm{C} 1>\mathrm{C} 2>\mathrm{C} 3)$. The reduced alkylation is consistent with the loss of alkyl side chains 342 during the combustion processes (Lima et al. 2005). Furthermore, different proportions of 343 fluoranthene, pyrene, phenanthrene and benzo[b+j]fluoranthenes in two pyrogenic sources, 344 probably discriminate also between different temperature combustion processes, such as motor 345 vehicle engines and open burning (Tobiszewski and Namiesnik 2012). In the range of higher 346 molecular weight, the HMW-PAHs benzo[e]pyrene/benzo[a]pyrene (BePy/BaPy) ratio is lower 
than 1 for both pyrogenic profiles (Fig. 2), suggesting non-atmospheric routes of entry and/or that

348 these compounds are not transported far from their emission source (Tobiszewski and Namiesnik 2012).

350 In the petrogenic source profile, alkyl-substituted compounds were dominant, with

351 characteristic "bell-shaped" patterns for phenanthrene/anthracene, fluoranthene/pyrene and 352 chrysene suites of compounds. In this petrogenic profile, relatively abundant sulphur heterocycle 353 homologues, such as alkyl-dibenzothiophenes, displaying a bell-shaped distribution may also be 354 noted. However, the significant presence of non-substituted benzonaphthothiophenes (mainly 355 benzo[b]naphtho[2,1-d]thiophene) may also indicate mixed sources of petrogenic and diesel356 combustion emissions (Larsen and Baker 2003). Furthermore, fairly elevated proportions of 357 higher molecular PAHs (benzopyrenes, indeno[1,2,3-cd]pyrene (IPy) and benzo[ghi]perylene 358 (BghiPy) may also imply a mixed source of PAH for this profile. For this reason, caution should 359 be exercised when interpreting the quantitative results of PAH apportionment by multivariate 360 receptor environment models (Laresen and Baker 2005).

361 The quantitative apportionment of PAH source contributions reveals significant geographical 362 differences (Fig. 3). Dominant petrogenic PAHs were found along the mid-Adriatic transect 363 (approximately 74\%) and in the Kaštela Bay (61\%). In the coastal sediments, contamination is 364 assigned about equally to petrogenic/pyrogenic sources of PAHs (47\% and 53\%, respectively), 365 whereas in Šibenik Bay a very high percentage is apportioned to the combustion compounds $366(81 \%)$. Despite generally lower levels of petroleum hydrocarbons along the mid-Adriatic and the 367 Croatian coast (Fig. 3), these results indicate that sediment contamination by petrogenic PAHs 368 may be spatially more important. This may also be consistent with the pathways of petroleum369 derived PAHs, which are more dispersed, originating from various oil spillages and all routine 370 leaks that accompany diverse maritime activities (oil cargo, harbour operations, regular and 
371 seasonal transport...). Whereas, the pyrogenic PAH inputs along the Croatian coast seem to be

372 more confined, being associated mainly with the urban/industrial point sources (Fig. 3). The

373 distribution of modelled concentrations of total PAHs, apportioned to three identified sources,

374 shows the peaks of high levels of petrogenic and pyrogenic PAHs, found repeatedly at the same

375 stations for all sampling periods in Kaštela Bay (station KB3 industrial port of Split) and in

376 Sibenik Bay (SB4, former ferroalloy plant, Fig. 3). Thus, it appears that contamination by PAHs

377 at these sites is not transient. The higher relative petrogenic contributions may also be seen in the

378 sediments facing the marina in Sibenik Bay (station SB1) and more generally in the whole

379 coastal area between Kaštela Bay and Dubrovnik (stations CS9, 10, 11 and 12). These areas are

380 definitely under high pressure by recreational coastal navigation. It also appears that the overall

381 source contribution determinations obtained by the ALS model compare generally very well with

382 the source indicators discussed above. The ratio of alkyl to parent PAH compounds

$383(\Sigma \mathrm{Alkyl} / \mathrm{SPAH})$ correlates very well with the estimated percent contribution of the petrogenic

384 PAH source, thus confirming that it is an excellent proxy for these source inputs (Fig. S-5).

385 However, pure source identification might be difficult and questionable. In receptor model 386 approaches, generally, data sets do not contain end-member reference source profiles (Comero et 387 al. 2009). PAH data reflect a mixture of sources and generally no single compound is the unique 388 tracer of a particular source. Furthermore, as identified in this study, a characteristic profile of 389 PAH sources assigns very broad classes (i.e. petroleum and combustion) that to a certain degree 390 overlap in their profile identification. In addition, such PAH classes are themselves mixtures of 391 compounds derived from multiple sources. Moreover, further identification, especially of 392 combustion sources, is generally needed, in order to resolve PAHs derived from biomass burning 393 and fossil fuel (coal and petroleum) combustion. This is valuable scientific information within the 394 framework of the current efforts for global characterization of pyrogenic carbon in climate 
395 change impact studies. In sedimentary records, PAHs may be used as molecular markers, tracing

396 fossil fuel-derived pyrogenic carbon (Hanke et al. 2017). This information is also required for

397 management decisions concerning environmental measures. In the present calculations, no

398 specific PAH source markers of wood combustion were used, such as selected alkylphenanthrene

399 isomers. Likewise, certain heavy molecular weight (302 MW) compounds (known as gasoline

400 and diesel combustion markers) were not included either (Ramdahl 1983, Benner et al. 1995,

401 Allen et al. 1998, Guillon et al. 2013). The addition of such compounds would possibly help to

402 further resolve characteristic source profiles and their contributions from our set of data.

403 Additional PAH markers, which were analyzed in the Croatian sediments (such as retene, a series

404 of dimethylphenanthrenes, naphto-fluorathenes/pyrenes and dibenzopyrenes) will be used in

405 further source characterization assessments. Nevertheless, the ALS method allowed us to assess

406 the modelling power of individual compounds. The benzo[b+j]fluoranthenes and fluoranthene

407 and pyrene compounds characterized two combustion sources, while the alkyl-substituted

408 signature homologues (phenanthrenes/anthracenes, fluranthenes/pyrenes and chrysenes and 409 dibenzothiophenes) delineate an oil source profile. Consequently, these results provide

410 preliminary reference data for source profiles and contributions concerning the contamination of

411 marine sediment by PAHs in the mid-Adriatic and along the Croatian coast.

412 ASSOCIATED CONTENT

413 Supporting information available. Additional information is included for all sampling stations

414 positions and coding, PAH analyses and data, PAH concentrations and ratios, as well as

415 additional figures.

416 AUTHOR INFORMATION

417 Corresponding Author 
418 *Jacek Tronczyński, Ifremer, BP21105, 44311 Nantes cedex 03, France; e-mail:

419 jtronczy@ifremer.fr; phone: +33 2403741 36; fax: +33 240374075.

\section{FUNDINGS}

This study was financially supported by Ifremer Centre Atlantique - Nantes, France; IOF-Split, Croatia and the Croatian Science Foundation (grant IP-2014-09-3606: "Marine plankton as a tool for assessment of climate and anthropogenic influence on the marine ecosystem - MARIPLAN").

The study was conducted within the EU FP7 $\mathrm{N}^{\circ} 287600$ PERSEUS project, which provided additional financial support. J. Mandić conducted her $\mathrm{PhD}$ at the University of Split and obtained a short-term fellowship at the Laboratoire de Biogéochimie des Contaminants Organiques Ifremer.

\section{References}

Allen, J.O., Durant, J.L., Dookeran, N.M., Taghizadeh, K., Plummer, E.F., Lafleur, A.L., Sarofim, A.F., Smith, K.A. (1998). Measurement of C24H14 polycyclic aromatic hydrocarbons associated with a size-segregated urban aerosol. Environ. Sci. Technol. 32, 1928-1932.

Azoury, S., Tronczyński , J., Chiffoleau, J.F., Cossa, D., Nakhle, K., Schmidt, S., Khalaf G. (2013). Historical Records of Mercury, Lead, and Polycyclic Aromatic Hydrocarbons Depositions in a Dated Sediment Core from the Eastern Mediterranean . Environ. Sci.Technol. 47(13), 7101-7109.

Barakat, A.O., Mostafa, A., Wade, T.L., Sweet, S.T., El Sayed, N.B. (2011). Distribution and characteristics of PAHs in sediments from the Mediterranean coastal environment of Egypt. Mar. Pollut. Bull. 62, 1969-1978.

Baumard, P., Budzinski, H., Garrigues, P. (1998). Polycyclic aromatic hydrocarbons in sediments and mussels of the western Mediterranean sea. Environ. Toxicol.Chem. 17, 765-776.

Baumard, P., Budziniski, H., Garrigues, P., Dizer, H., Hansen, P.D. (1999). Polycyclic aromatic hydrocarbons in recent sediments and mussels (Mytilus edulis) from the western Baltic Sea: Occurrence, bioavailability and seasonal variations. Mar. Environ. Res. 47, 17-47.

Benlahcen, K. T., Chaoui, A., Budzinski, H., Bellocq, J. Garrigues, P. H. (1997). Distribution and sources of polycyclic aromatic hydrocarbons in some Mediterranean coastal sediments. Marine Pollut. Bull. 34(5), 298-305. 
Benner, B.A., Wise, S.A., Currie, L.A., Klouda, G.A., Klinedinst, D.B., Zweidinger, R.B., Stevens, R.K., Lewis, C.W. (1995) Distinguishing the contributions of residential wood combustion and acid mobile source emissions using relative concentrations of dimethylphenantrene isomers. Environ. Sci. Technol. 29, 2382-2389.

Bertolotto, R. M., Ghioni, F., Frignani, M., Alvarado-Agilar, D., Belluci, L. G., Cuneo, C., Picca, M. R., Gollo, E. (2003). Polycyclic aromatic hydrocarbons in surficial coastal sediment of the Ligurian Sea. Mar. Pollut. Bull. 46, 903-917.

Bužančić, M., Ninčević, G. Ž. , Marasović, I., Kušpilić, G., Grbec, B. (2016). Eutrophication influence on phytoplankton community composition in three bays on the eastern Adriatic coast. Oceanologia 58(4), 302-316.

Cathalot, C., Rabouille, C., Tisnérat-Laborde, N., Toussaint, F., Kerhervé, P. , Buscail, R., Bowles, K. , Sun, M-Y. , Tronczyński , J., Lansard, B., Treignier, C., Pastor, L., Tesi, T., Miserocchi, S., Azoury, S. (2013). The fate of river organic carbon in coastal areas: a study in the Rhone River delta using multiple isotopic $(13 \mathrm{C}, 14 \mathrm{C})$ and organic tracers. Geochim. Cosmochim. Acta 118, 33-55.

Chen, Y.J., Sheng, G.Y., Bi, X.H., Feng, Y.L., Mai, B.X., Fu, J.M. (2005). Emission factors for carbonaceous particles and polycyclic aromatic hydrocarbons from residential coal combustion in China. Environ. Sci. Technol. 39, 1861-1867.

Christensen, J.H., Hansen, A.B., Tomasi, G., Mortensen, J., Andersen, O. (2004). Integrated methodology for forensic oil spill identification. Environ. Sci.Technol. 38, 2912-2918.

Comero S., Capitani L., Gawlik B.M. (2009). Positive Matrix Factorisation (PMF). An introduction to the chemometric evaluation of environmental monitoring data using PMF. JRC Scientific and Technical reports EUR 23946 EN-2009. European Commission Joint Research Centre, Institute for Environment and Sustainability, Ispra, Italy, pp 1-59.

Dachs, J., Lohmann, R., Ockenden, W.A., Mejanelle, L., Eisenreich, S.J., Jones, K.C. (2002). Oceanic biogeochemical controls on global dynamics of persistent organic pollutants. Environ. Sci.Technol., 36, 4229-4237.

De Luca, G., Furesi, A., Leardi, R., Micera, G., Panzanelli, A., Piu, P.C., Sanna, G. (2004). Polycyclic aromatic hydrocarbons assessment in the sediments of the Porto Tores Harbor (Northern Sardinia, Italy). Mar. Chem. 86, 15-32.

Deyme, R., Bouloubassi, I., Taphanel-Valt, M.H., Miquel, J.C., Lorre, A., Marty, J.C., Mejanelle, L. (2011). Vertical fluxes of aromatic and aliphatic hydrocarbons in the Northwestern Mediterranean Sea. Environ. Pollut. 159, 3681-3691.

Di Leonardo, R., Vizzini, S., Bellanca, A., Mazzola, A. (2009). Sedimentary record of anthropogenic contaminants (trace metals and PAHs) and organic matter in a Mediterranean coastal area (Gulf of Palermo, Italy). J. Mar. Syst. 78, 136-145.

Dickens A. F., Gelinas Y., Masiello C. A., Wakeham S. Hedges J. I. (2004). Reburial of fossil organic carbon in marine sediments. Nature 427, 336-339. 
Douglas, G.S., Bence, A.E., Prince, R.C., McMillen, S.J., Butler, E.L. (1996) Environmental stability of selected petroleum hydrocarbon source and weathering ratios. Environ. Sci.Technol. 30, 2332-2339.

Durant, J.L., Lafleur, A.L., Plummer, E.F., Taghizadeh, K., Busby, W.F., Thilly, W.G. (1998). Human lymphoblast mutagens in urban airborne particles. Environ. Sci.Technol. 32, 1894-1906.

EEA (2013). European Union emission inventory report 1990-2011 under the UNECE Convention on Long-range Transboundary Air Pollution (LRTAP). European Environmental Agency Technical Report 10/2013. Luxembourg: Office for Official Publications of the European Union. Available from: http://www.eea.europa.eu/publications/eu-emission-inventory-reportlrtap, accessed 9 October 2014.

EU (2013) Directive 2013/39/EU amending Directives 2000/60/EC and 2008/105/EC as regards priority substances in the field of water policy.

EPA Priority Pollutant List (2014) 40 CFR Part 423, Appendix A. https://www.epa.gov/sites/production/files/2015-09/documents/priority-pollutant-list-epa.pdf.

Fraser, M.P., Cass, G.R., Simoneit, B.R.T., Rasmussen, R.A. (1998). Air quality model evaluation data for organics. 5. C-6-C-22 nonpolar and semipolar aromatic compounds. Environ. Sci.Technol. 32, 1760-1770.

Fernandez, P., Vilanova, R. M., Martinez, C., Appleby, P. Grimalt, J. O. (2000). The historical record of atmospheric pyrolytic pollution over Europe registered in the sedimentary PAH from remote mountain lakes. Environ. Sci.Technol. 34(10), 1906-1913.

Gogou, A., Bouloubassi, I., Stephanou, E.G. (2000). Marine organic geochemistry of the Eastern Mediterranean: 1. Aliphatic and polyaromatic hydrocarbons in Cretan Sea surficial sediments. Mar. Chem. 68, 265-282.

Gomez-Gutierrez, A., Garnacho, E., Bayona, J.M., Albaiges, J. (2007). Assessment of the Mediterranean sediments contamination by persistent organic pollutants. Environ. Pollut. 148, 396-408.

Gonul, L. T., Kucuksezgin, F. (2012). Aliphatic and polycyclic aromatic hydrocarbons in the surface sediments from the Eastern Aegean: assessment and source recognition of petroleum hydrocarbons. Environ. Sci. Pollut. Res. 19(1), 31-41.

Grande, B.V. Manne, R. (2000). Use of convexity for finding pure variables in two way data from mixtures". Chemometr. Intell. Lab. 50, 19-33.

Guillon, A., Le Menach, K., Flaud, P.M., Marchand, N., Budzinski, H., Villenave, E. (2013). Chemical characterization and stable carbon isotopic composition of particulate Polycyclic Aromatic Hydrocarbons issued from combustion of 10 Mediterranean woods. Atm. Chem. Phys. $13,2703-2719$.

Guo, Z., Lin, T., Zhang, G., Zheng, M., Zhang, Z., Hao, Y., Fang, M. (2007). The sedimentary fluxes of polycyclic aromatic hydrocarbons in the Yangtze River Estuary coastal sea for the past century. Sci. Total. Environ. 386, 33-41. 
Hanke U. M., Reddy C. M., Braun A. L.L., Coppola A. I., Haghipour N., McIntyre C. P., Wacker L., Xu L., McNichol A. P., Abiven S., Schmidt M. W.I., Eglinton T. I. (2017). What on Earth have we been burning? Deciphering sedimentary records of pyrogenic carbon. Environ. Sci.Technol. 51 (21), 12972-12980.

Jenkins, B.M., Jones, A.D., Turn, S.Q., Williams, R.B. (1996). Emission factors for polycyclic aromatic hydrocarbons from biomass burning. Environ. Sci.Technol. 30, 2462-2469.

Johansson, L.S., Leckner, B., Gustavsson, L., Cooper, D., Tullin, C., Potter, A. (2004). Emission characteristics of modern and old-type residential boilers fired with wood logs and wood pellets. Atmos. Environ. 38, 4183-4195.

Karickhoff, S.W., Brown, D.S., Scott, T.A. (1979). Sorption of hydrophobic pollutants on natural sediments. Water Res. 13, 241-248.

Kumata, H., Eisukesakuma, M., Kitaofujiwara, T., Minoruyoneda, M., Kishibata, Y. (2006). Compound Class Specific 14C Analysis of Polycyclic Aromatic Hydrocarbons Associated with PM10 and PM1.1 Aerosols from Residential Areas of Suburban Tokyo. Environ. Sci. Technol. 40,11 .

Kušpilić, G. (2005) Anthropogenic inputs, ecological state and impact of biodiversity in the marine environment. UNDP/GEF "Coast" project, Conservation and sustainable use of biodiversity in the Dalmatian Coast through greening coastal development. Project PDF B phase, Technical Report., Split. 50pp

Laflamme, R.E., Hites, R.A. (1978). The global distribution of polycyclic aromatic hydrocarbons in recent sediments. Geochim. Cosmochim. Acta 42, 289-303.

Lang. Y.H., Yang. X., Wang. H., Yang. W., Li, G.L. (2013). Diagnostic ratios and positive matrix factorization to identify potential sources of PAHs in sediments of the Rizhao Offshore, China. Polycycl. Aromat. Compd. 33, 161-172.

Larsen R., Baker J. (2003). Source Apportionment of Polycyclic Aromatic Hydrocarbons in the Urban Atmosphere: A Comparison of Three Methods. Environ. Sci. Technol. 37, 1873-1881.

Law, R.J., Kelly, C.A., Nicholson, M.D. (1999). Polycyclic aromatic hydrocarbons (PAH) in shellfish affected by the Sea Empress oil spill in Wales in 1996. Polycyclic Aromatic Compounds 17, 229-239.

Lee, R.G.M., Coleman. P., Jones, J. L., Jones, K. C., Lohmann, R. (2005) Emission factors and importance of PCDD/Fs, PCBs, PCNs, PAHs and PM10 from the domestic burning of coal and wood in the UK. Environ. Sci. Technol. 39, 1436-1447.

Li A., Jang J.K., Scheff, P. (2003). Application of EPA CMB8.2 Model for Source apportionment of Sediment PAHs in Lake Calumet, Chicago. Environ. Sci. Technol. 37, 29582965.

Lima, A. L. C., Farrington, J. W. et Reddy, C. M. (2005). Combustion-derived polycyclic aromatic hydrocarbons in the environment - A review. Environ. Forensics 6(2), 109-131. 
560 Lipiatou, E., Tolosa, I., Simo, R., Bouloubassi, I., Dachs, J., Marti, S., Sicre, M.A., Bayona, J.M., 561 Grimalt, J.O., Saliot, A., Albaiges, J. (1997). Mass budget and dynamics of polycyclic aromatic 562 hydrocarbons in the Mediterranean Sea. Deep-Sea Research Part II-Topical Studies, 563 Oceanography 44, 881-905.

564 Mandalakis, M., Gustafsson, O., Reddy, C. Xu, L. (2004). Radiocarbon apportionment of fossil versus biofuel combustion sources of polycyclic aromatic hydrocarbons in the Stockholm metropolitan area. Environ. Sci. Technol. 38, 5344-5349.

Mandalakis, M., Gustafsson, O., Alsberg, T., Lenaegeba, L., Reddy, C., Xu L., Klanova J., Holubek I., Stephanou, E. (2005). Contribution of Biomass Burning to Atmospheric Polycyclic Aromatic Hydrocarbons at Three European Background Sites. Environ. Sci. Technol. 39, 29762982.

571 Marini, M., Maselli, V., Campanelli, A., Foglini, F., Grilli, F. (2015). Role of the Mid-Adriatic 572 deep in dense water interception and modification. Mar. Geol. 375, 5-14.

Mcare, C., Snape, C. Gongsun, C., Fabbri, D., Tatari, D., Trmobini, C., Fallick A. (2000). Use of Compound-Specific Stable Isotope Analysis to Source Anthropogenic Natural Gas-Derived Polycyclic Aromatic Hydrocarbons in a Lagoon Sediment. Environ. Sci. Technol. 34, 22. Middle and Southern Adriatic Sea as a result of intensive ship traffic. Acta Adriat. 56(2), 145578156.

Mzoughi, N., Chouba, L. (2011). Distribution of trace metals, aliphatic hydrocarbons and polycyclic aromatic hydrocarbons in sediment cores from the Sicily Channel and the Gulf of Tunis (south-western Mediterranean Sea). Environ. Sci.Technol. 32(1), 43-54.

Neff, J.M. (1979). Polycyclic aromatic hydrocarbons in the aquatic environment : source, fates and biological effects. Applied Science Publishers.

584 Neff, J.M. (2002). Bioaccumulation in marine organisms : effects from contaminants from oil 585 well produced water. Elsevier.

OSPAR/ICES Report (2004). On the evaluation and update of background reference concentrations (B/RCs) and ecotoxicological assessment criteria (EACs) and how these assessment tools should be used in assessing contaminants in water, sediment and biota. Ices/Ciem 124 p. https://www.ospar.org/documents?v=6989.

590 Ostrowska A, Gawliński S, Szczubiałka Z. (1991). Methods of analysis and evaluation of 591 properties of soils and plants (in Polish) Warszawa: Instytut Ochrony Środowiska.

592 Pacyna, J.M., Breivik, K., Munch, J., Fudala, J. (2003). European atmospheric emissions of 593 selected persistent organic pollutants, 1970-1995. Atmos. Environ. 37, S119-S131.

594 Pirouette, Infometrix Inc., (2014) Multivariate Data Analysis Software 595 http://www.infometrix.com/. 
Ponce-Vélez, G., Botello, A.V., Díaz-González, G. (2006). Organic and inorganic pollutants in marine sediments from northern and southern continental shelf of the Gulf of Mexico. Inter. J. Environ. Pollut. 26, 1/2(3).

Ramdahl, T. (1983) Retene - A molecular marker of wood combustion in ambiant air. Nature 306, 580-583.

Reddy C., Pearson A., Xu L., Mcnichol A., Benner Jr. B., Wise S., Curie L., Eglinton, G . (2002). Radiocarbon as a Tool To Apportion the Sources of Polycyclic Aromatic Hydrocarbons and Black Carbon in Environmental Samples. Environ. Sci. Technol. 36, 1774-1782.

Savinov, V. M., Savinova, T. N., Matishov, G. G., S. Dahle, S., Næs, K. (2003). Polycyclic aromatic hydrocarbons (PAHs) and organochlorines (OCs) in bottom sediments of the Guba Pechenga, Barents Sea, Russia. Sci. Total Environ. 306, 39-56.

Shen, H., Huang, Y., Wang, R., Zhu, D., Li, W. (2013). Global atmospheric emissions of polycyclic aromatic hydrocarbons from 1960 to 2008 and future predictions. Environ. Sci. Technol. 47(12), 6415-24.

Short, J.W., Harris, P.M. (1996) Petroleum hydrocarbons in caged mussels deployed in Prince William Sound after the Exxon Valdez oil spill, American Fisheries Society Symposium, pp. 2939.

Sprovieri, M., Feo, M. L., Prevedello, L., Salvagio Manta, D., Sammartino, S., Tamburrino, S., Marsella, E. (2007). Heavy metals, polycyclic aromatic hydrocarbons and polychlorinated biphenyls in surface sediments of the Naples harbour (southern Italy). Chemosphere, 67, 9981009.

Stogiannidis E., Laane R. (2015). Source Characterization of Polycyclic Aromatic Hydrocarbons by Using Their Molecular Indices: An Overview of Possibilities; Springer Int. D.M. Whitacre (ed.), Rev. Environ. Contam. T. 234, 49-133.

Stout S.A., Graan T.P. (2010). Quantitative source apportionment of PAHs in sediments of Little Menomonee River, Wisconsin: weathered creosote versus urban background. Environ. Sci. Technol. 44, 2932-2939.

Tauler, R., Kowalski, B.R., Fleming, S. (1993). Multivariate curve resolution applied to spectral data from multiple runs of an industrial process. Anal. Chem. 65(15), 2040-2047.

Tobiszewski M., Namiesnik J. (2012). PAH diagnostic ratios for the identification of pollution emission sources. Environ. Pollut. 162, 110-119.

Tolosa I., Bayona J. M. Albaiges, J. (1996). Aliphatic and polycyclic aromatic hydrocarbons and sulfur/oxygen derivatives in northwestern Mediterranean sediments: Spatial and temporal variability, fluxes, and budgets. Environ. Sci. Technol. 30 (8), 2495-2503.

Tronczyński , J., Munschy, C., Heas-Moisan, K., Guiot, N., Truquet, I., Olivier, N., Men, S., Furaut, A. (2004). Contamination of the Bay of Biscay by polycyclic aromatic hydrocarbons (PAHs) following the T/V "Erika" oil spill. Aquatic Living Resources 17 (3), 243-259. 
633 Tsapakis, M., Apostolaki, M., Eisenreich, S., Stephanou, E. G. (2006). Atmospheric deposition 634 and marine sedimentation fluxes of polycyclic aromatic hydrocarbons in the eastern 635 Mediterranean basin. Environ. Sci. \& Technol. 40 (16), 4922-4927.

636 Tsapakis, M., Stephanou, E. G. Karakassis, I. (2003). Evaluation of atmospheric transport as a 637 nonpoint source of polycyclic aromatic hydrocarbons in marine sediments of the Eastern 638 Mediterranean. Mar. Chem. 80 (4), 283-298.

639 UNEP (2016) Agenda item 5. Review of Proposed Background Concentrations (BC)/Background 640 Assessment Criteria (BACs)/Environmental Assessment Criteria (EACs) for Contaminants and 641 Biomarkers at Mediterranean and Regional Scales ( UNEP(DEPI)/MED WG.427/7, version 18 642 September 2016 ), 2016.

643 Venkatesan, M. I. (1988). Occurence and possible sources of perylene in marine sediments - a 644 review. Mar. Chem. 25 (1), 1-27.

645 Wakeham, S. G., Schaffner, C., Giger, W. (1980). Polycyclic aromatic hydrocarbons in recent 646 lake sediments.1. Compounds having anthropogenic origins. Geochim. Cosmochim. Acta 44(3), $647 \quad 403-413$.

648 Wenthworth, C. K. (1922). A scale of grade and class term for class term for classifing 649 sediments. J.Geology 30, 377-392.

650 White H., Reddy C., Eglinton T. (2005). Isotopic Constraints on the Fate of Petroleum Residues 651 Sequestered in Salt Marsh Sediments. Environ. Sci. Technol. 39, 2545-2551.

652 Yunker, M.B., Macdonald, R.W., Vingarzan, R., Mitchell, R.H., Goyette, D., Sylvestre, S. (2002) 653 PAHs in the Fraser River basin: a critical appraisal of PAH ratios as indicators of PAH source 654 and composition. Org. Geochem 33, 489-515.

655 Zhao, Y., Kreisberg, N.M., Worton, D.R., Isaacman, G., Weber, R.J., Liu, S. Day, D.A., Russell, 656 L.M., Markovic, M.Z., VandenBoer, T.C., Murphy, J.G., Hering, S.V., Goldstein, A.H. (2013). 657 Insights into secondary organic aerosol formation mechanisms from measured gas/particle 658 partitioning of specific organic tracer compounds. Environ. Sci. Technol. 47(8), 3781-7.

659 Zhang, X.L., Tao, S., Liu, W.X., Yang, Y., Zuo, Q., Liu, Z. (2005). Source diagnostics of 660 polycyclic aromatic hydrocarbons based on species ratios: A multimedia approach. Environ. Sci. 661 Technol. 39, 9109-9114.

662 Zhang, Y., Tao, S. (2009). Global atmospheric emission inventory of polycyclic aromatic 663 hydrocarbons (PAHs) for 2004. Atmos. Environ. 43, 812-819.

664 Zhou, J. L., Maskaoui, K. (2003). Distribution of polycyclic aromatic hydrocarbons in water and 665 surface sediments from Daya Bay, China. Environ. Pollut. 121, 269-281. 
669 Table 1. Summed concentration of PAHs ( $\mu \mathrm{g} \cdot \mathrm{kg}^{-1}$ dry weight) in the surface sediments of the

670 offshore mid-Adriatic and along the Croatian coast.

\begin{tabular}{|c|c|c|c|c|c|c|c|c|}
\hline Zone & & Min & 1stQu. & Median & 3rdQu. & Max & Average & $N$ \\
\hline \multirow[t]{4}{*}{ Transect } & $\sum \mathrm{PAH}$ & 8.50 & 9.04 & 17.34 & 45.34 & 117.2 & 34.16 & 9 \\
\hline & $\sum \mathrm{C}-\mathrm{PAH}$ & 2.95 & 4.32 & 8.07 & 34.39 & 135.4 & 31.08 & 9 \\
\hline & $\sum$ S-PAH & 0.336 & 0.465 & 0.782 & 1.87 & 4.20 & 1.38 & 9 \\
\hline & $\sum \mathrm{CS}-\mathrm{PAH}$ & 0.292 & 1.16 & 2.06 & 3.46 & 13.27 & 3.49 & 9 \\
\hline \multirow[t]{4}{*}{ Coast } & $\sum \mathrm{PAH}$ & 81.24 & 124.4 & 148.7 & 357.1 & 1705 & 395.5 & 12 \\
\hline & $\sum \mathrm{C}-\mathrm{PAH}$ & 31.09 & 46.80 & 109.7 & 254.5 & 831.7 & 227.0 & 12 \\
\hline & $\sum \mathrm{S}-\mathrm{PAH}$ & 3.03 & 4.99 & 6.707 & 17.38 & 64.96 & 15.68 & 12 \\
\hline & $\sum \mathrm{CS}-\mathrm{PAH}$ & 1.76 & 7.77 & 18.36 & 44.02 & 157.5 & 42.25 & 12 \\
\hline \multirow[t]{4}{*}{ Kaštela } & $\sum \mathrm{PAH}$ & 114.4 & 134.6 & 330.9 & 521.9 & 1114 & 399.0 & 9 \\
\hline & $\sum \mathrm{C}-\mathrm{PAH}$ & 17.68 & 82.52 & 197.1 & 440.2 & 936.9 & 327.0 & 9 \\
\hline & $\sum \mathrm{S}-\mathrm{PAH}$ & 2.23 & 12.11 & 15.25 & 42.76 & 59.9 & 26.3 & 9 \\
\hline & $\sum \mathrm{CS}-\mathrm{PAH}$ & 2.40 & 27.75 & 49.93 & 161.8 & 331.6 & 107.7 & 9 \\
\hline \multirow[t]{4}{*}{ Šibenik } & $\sum \mathrm{PAH}$ & 4629 & 6049 & 6603 & 13018 & 18348 & 9614 & 17 \\
\hline & $\sum \mathrm{C}-\mathrm{PAH}$ & 1290 & 2456 & 3051 & 4892 & 5770 & 3416 & 17 \\
\hline & $\sum \mathrm{S}-\mathrm{PAH}$ & 101.7 & 232.8 & 265.8 & 310.2 & 514.0 & 286.6 & 17 \\
\hline & $\sum \mathrm{CS}-\mathrm{PAH}$ & 119.3 & 174.4 & 230.4 & 382.9 & 976.7 & 327.3 & 17 \\
\hline
\end{tabular}

671 इ PAH: Sum of unsubstituted compounds phenanthrene, anthracene, fluoranthene, pyrene, benz $[a]$ anthracene, chrysene + 672 triphenylene, benzo[ $b]$ fluoranthene+ benzo[j]fluoranthene, benzo[k]fluoranthene, benzo $[a]$ pyrene, benzo[e]pyrene, indeno[1,2,3-

$673 c d]$ pyrene, dibenz $[a h]$ anthracene, benzo[ghi]perylene.

$674 \Sigma$ C-PAH: Sum of alkyl-phenanthrenes / anthracenes, alkyl-fluoranthenes / pyrenes, alkyl-chrysenes, alkyl-benzofluoranthenes,

$675 \quad \Sigma$ S-PAH: Sum of unsubstituted dibenzothiophene and three isomers of benzonaphthothiophenes.

$676 \Sigma$ CS-PAH: Sum of alkyl- substituted dibenzothiophnes and benzonaphthothiophenes. 
680

681

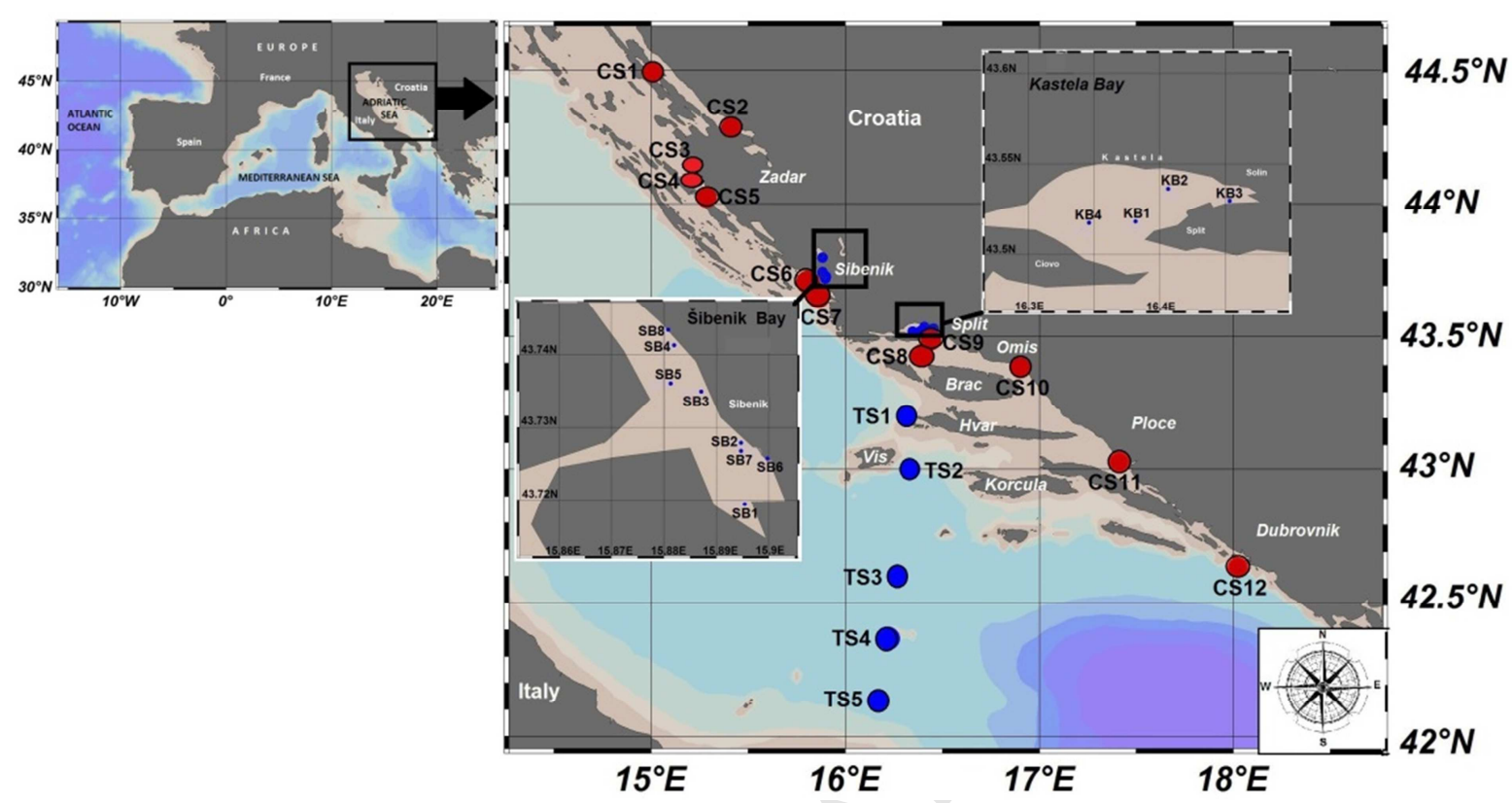

683 Figure 1. Map showing positions of the surface sediment sampling stations in four study areas:

684 the mid-Adriatic transect, a coastal survey north-west - south-east, Šibenik and Kaštela bays.

685

686

687

688 
689

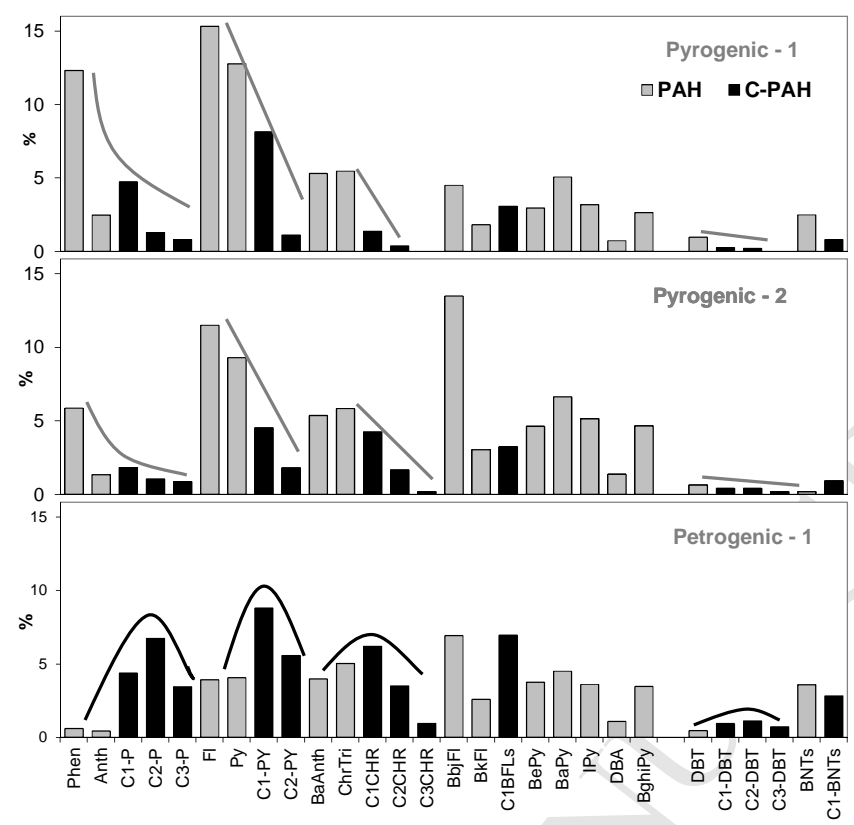

691 Figure 2. PAH source profiles obtained by ALS Alternating Least Square calculation 692 (Pirouette, Infometrix 2014). Abundances (weight \%) of parent individual compounds (PAH) and 693 of summed alkyl-substituted homologues (C1 mono-. C2 di- and C3 three-methyl substituted 694 PAH). Unresolved by GC-MS. PAH isomers are given together (triphenylene from chrysene and 695 benzo[b]fluoranthene from benzo[j]fluoranthene). For PAH abbreviations see Table S-3. 
698

699

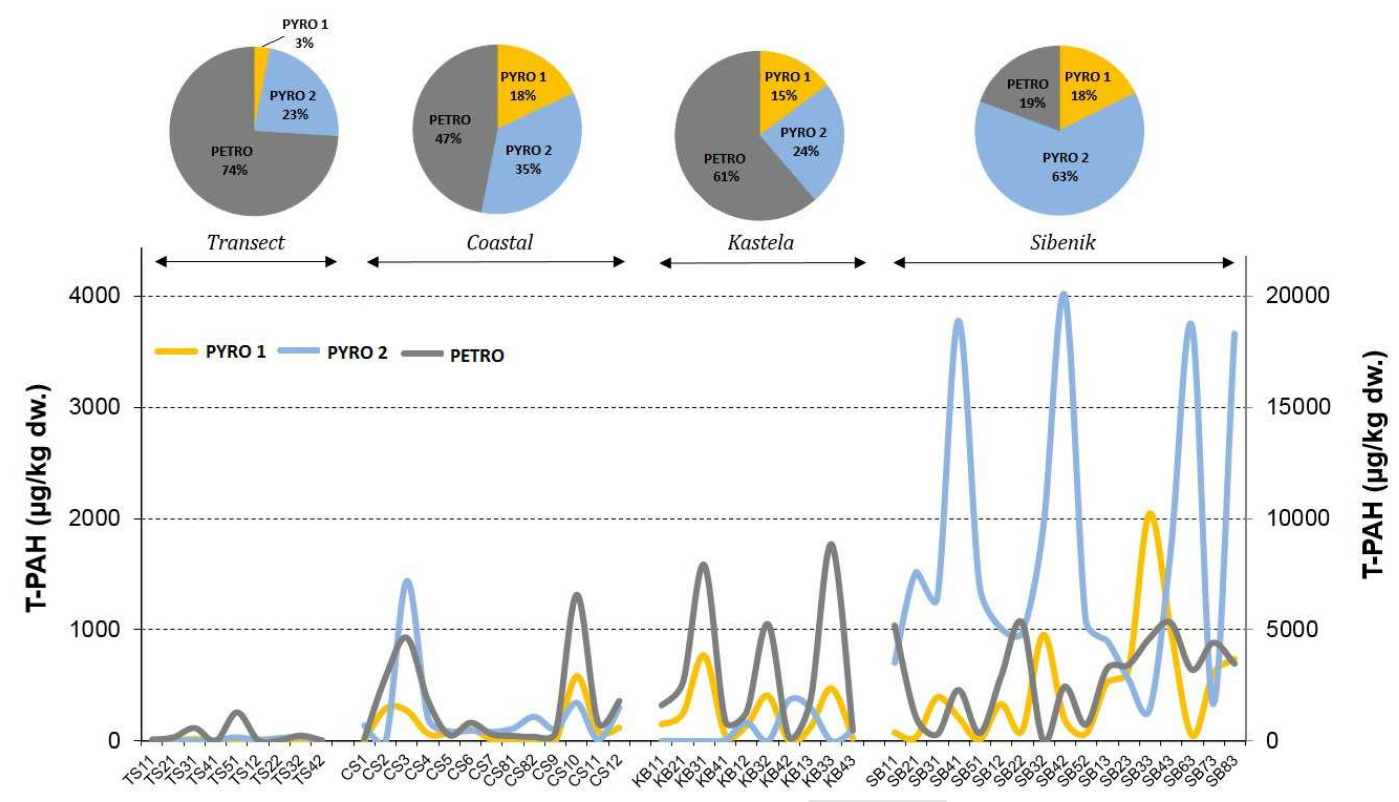

700 Figure 3. Distributions of modelled total T-PAH concentrations ( $\mu \mathrm{g} / \mathrm{kg} \mathrm{d.w}$.) apportioned into

701 two pyrogenic and one petrogenic source in each studied area; the Sibenik Bay concentrations are

702 given with right $\mathrm{y}$-axis; Upper pies show summed weight percent of total source contributions for

703 each area. All results are based on an alternative least square ALS-model.

704

705

706

707

708

709

710

711 